\title{
A comparative study to develop calcium, zinc, and antioxidant rich drinking yoghurt products using plant and pharmaceutical ingredients
}

\author{
Jayani Samarathunga ${ }^{1 *}$, Madhura Jayasinghe1, Maharsha Edirisinghe ${ }^{2}$, Isuru Wijesekara ${ }^{1}$, Piumi \\ Abeysundara1 ${ }^{1}$, Afshan Shafi ${ }^{3}$, Umar Farooq ${ }^{3}$, Subhashinie Senadheera ${ }^{4}$ \\ ${ }^{1}$ Department of Food Science and Technology, Faculty of Applied Sciences, University of Sri Jayewardenepura, Gangodawila, \\ Nugegoda, Sri Lanka \\ ${ }^{2}$ MILCO (Pvt) Ltd., No.45, Nawala Road, Narahenpita, Colombo, Sri Lanka \\ ${ }^{3}$ Department of Food Science and Technology, MNS-University of Agriculture, Multan, Pakistan \\ ${ }^{4}$ Department of Biochemistry, Faculty of Medicine and Allied Sciences, Rajarata University of Sri Lanka, Saliyapura, Sri Lanka
}

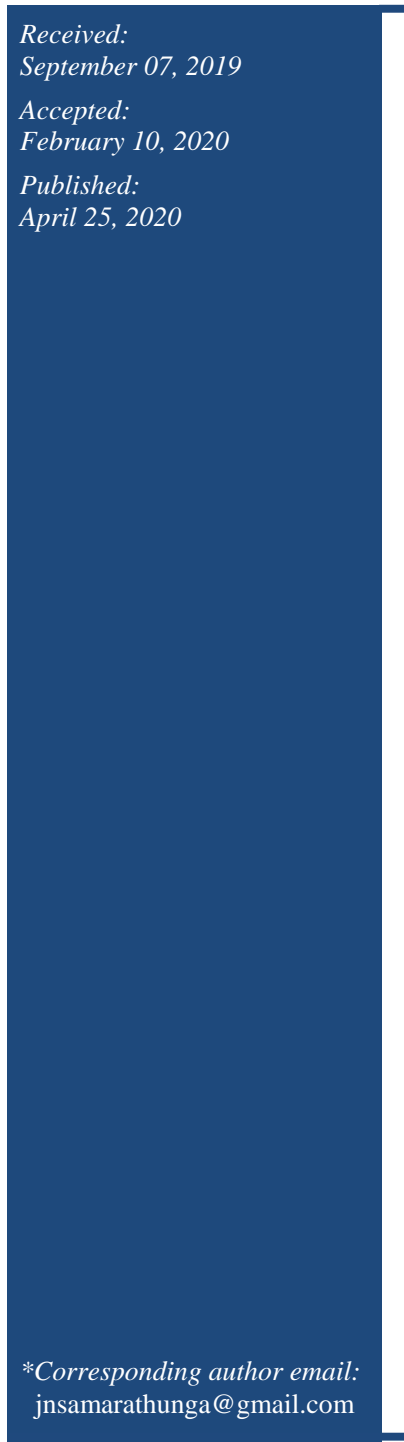

\begin{abstract}
Today, people in the world hungers natural foods. This study is an attempt taken to investigate the compatibility of utilizing plant sources in fortification rather than pharmaceutical sources. Two sets of drinking yoghurt products were prepared using cow's milk and fortified using selected plant and pharmaceutical sources of $\mathrm{Ca}$ and $\mathrm{Zn}$ separately; as they fulfil 1/3,1/2 and 2/3 of Reference Dietary Intakes (RDI) of Ca and Zn. Drinking yoghurt fortified at $50 \% \mathrm{RDI}$ of $\mathrm{Ca}$ with plant extracts elicited best sensory properties among all products. Incorporation of Moringa oleifera dried leaf powder extract and Phyllanthus emblica fruit extract had significantly increased the mineral composition compared to plain drinking yoghurt $(\mathrm{p}<0.05)$. All drinking yoghurts incorporated with plant ingredients had significantly higher $(\mathrm{p}<0.05)$ antioxidant activity (Range: 52.08 \pm 0.02 $91.69 \pm 0.00 \%)$ and total phenolic contents $(2.29-3.60 \mathrm{mg} \mathrm{GAE} / \mathrm{g})$ than the control. All products fortified with $\mathrm{Ca}$ and $\mathrm{Zn}$ using pharmaceutical sources showed significantly lower $(\mathrm{p}<0.05)$ antioxidant activity. Microbiological evaluation did not elicit any significant difference $(p>0.05)$ after subjected to mineral fortification from either plant or pharmaceutical sources. During the shelf life evaluation, quick increment in $\mathrm{pH}$ was observed in products with pharmaceutical ingredients than the control. Syneresis was higher in samples with plant ingredients than the control and pharmaceutical ingredient added products but was not greatly affecting the product stability during two weeks of shelf life period. Overall, the incorporation of M. oleifera and $P$. emblica can be concluded as reliable option for dairy products such as drinking yoghurts; to fortify them with high $\mathrm{Ca}$ and $\mathrm{Zn}$, to enhance antioxidant properties as well as to maintain product stability and organoleptic properties.
\end{abstract}

Keywords: Phyllanthus emblica, Moringa oleifera, Ca fortification, Zn fortification, Antioxidant activity

\section{How to cite this:}

Samarathunga J, Jayasinghe M, Edirisinghe M, Wijesekara I, Abeysundara P, Shafi A, Farooq U and Senadheera S, 2020. A comparative study to develop calcium, zinc, and antioxidant rich drinking yoghurt products using plant and pharmaceutical ingredients. Asian J. Agric. Biol. 8(2):174-185. DOI: https://doi.org/10.35495/ajab.2019.08.360

This is an Open Access article distributed under the terms of the Creative Commons Attribution 3.0 License. (https://creativecommons.org/licenses/by/3.0), which permits unrestricted use, distribution, and reproduction in any medium, provided the original work is properly cited. 


\section{Introduction}

People in the world follow various food patterns. That is not only for the survival, but also it manifests their social status and psychology. Dietary choices of many social segments in the modern day are heavily affected by their busy lifestyles and so they lack the required levels of Calcium (Ca), Zinc ( $\mathrm{Zn})$ and antioxidants in them. Moreover, some people choose vegetarian diets as they believe it is healthier and morally acceptable (Meister, 1997). Vegetarianism is rapidly becoming popular in regions like Europe (Ruby, 2012). Among all countries, India has largest number of vegetarians/ vegans due to cultural and religious traditions. Also, Nepal and Sri Lanka, the vegetarian population is a considerably high percentage. In most of the other countries, vegetarianism is popular based on animal rights, environmental protection and mainly on health concerns. A typical vegan/ vegetarian diet is rich in antioxidants but, vegetarians who refrain from fish, meat products and eggs for long term may lack the necessary amounts of $\mathrm{Ca}$ and $\mathrm{Zn}$ (Larsson and Johansson, 2002). Due to the deficiency of certain nutrients in some vegetarian diets, people who are strict vegetarians, face nutritional deficiency disorders (Scrimshaw, 1996). Such common nutrients deficient in vegan diets are $\mathrm{u}-3$ polyunsaturated fatty acids, Iron $(\mathrm{Fe}), \mathrm{Ca}$, vitamin $\mathrm{B} 12, \mathrm{Zn}$ and vitamin $\mathrm{D}$ (Phillips, 2005). Fe and Ca compete with each other during the small intestinal absorption and therefore, only one will get absorbed to a greater extent. Mostly the winner is Iron (Scheers, 2013). Nutrient fortification has brought an impressive solution for the stated problem. This can be taken as a responsibility as well as an opportunity by food producers; to produce goods that would fulfil a high percentage of $\mathrm{RDI}$ of $\mathrm{Ca}$ and $\mathrm{Zn}$ by a single portion. If those products could be enriched with antioxidants, would suit the busy lifestyles of modern employees. One objective of this study was conducted to address that requirement. Mineral fortification in dairy products has become the major reason to make dairy products dominant in global functional foods market (Gerhart and Schottenheimer, 2013). Especially minerals like Ca, Magnesium ( $\mathrm{Mg}$ ) or $\mathrm{Zn}$ can offer a great solution to top health topics like bone health, immunity, energy or cognitive functions (FAO/WHO, 2002). As dairy products are a complex food matrix (Deeth and Lewis, 2014), feasibility of mineral addition has to be considered and high fortification levels are challenging. Applications become successful only with the right selection of the appropriate mineral compound combined with the correct incorporation method.

Utilization of fruits and vegetable sources are becoming popular because of no side effects and cost effective (Sindu et al., 2019). But selecting plant sources to be incorporated in dairy products is extremely challenging, as it is difficult to get all necessary nutrients "effectively" by them. Phytochemicals like phytates, oxalates, tannins and other anti-nutritional factors in plant materials reduce the bioavailability of minerals (Allen et al., 2014). Besides, milk is already considered a good Ca source by the public, and to fortify it further with $\mathrm{Ca}$; have to find extremely rich plant oriented $\mathrm{Ca}$ sources with better bioavailability and easy extraction processes. Rice bran is a good source of trace minerals and is much superior to other cereals. Current findings have shown that brown rice has higher element concentration than white rice (Gee Ong et al., 2019). There is a need to assess the bioavailability of minerals from rice bran, especially of $\mathrm{Ca}, \mathrm{Fe}$ and $\mathrm{Zn}$, considering its high phytate content. Processing techniques like milling in cereals, blanching in Moringa oleifera leaves reduce phytate content (Sallau et al., 2012).

Mineral fortification merely relies on Recommended Dietary Intake (RDI) of minerals since overdose may result in adverse effects. RDI values reflect the health limits for an individual associated with some factors like age, gender and other safety factors (Otten et al., 2006). Most of the dietary supplements are available as separate capsules/ tablets/ syrups. Hence, to obtain all the deficient nutrients in a vegetarian friendly diet, an individual should consume a significant number of capsules/ supplements which is less palatable and less affordable. Due to low feasibility in obtaining all these supplements together, most of the individuals intend to use one or few sources at a time and face other nutritional deficiencies. According to the statistical data from a survey done in USA has found that $\mathrm{Ca}$ intakes were higher for men and women who took daily supplements with calcium compared with those who seldom or never took supplements (Ackley et al., 1983).

Utilization of Moringa oleifera as plant sources in mineral fortification provides additional benefits to humans. Antioxidant property (Pakade et al., 2013), anti-ulcer effect, anti-microbial effects (Peixoto et al., 2011), anti hyperglycemic property (Tende et al., 2011), anti-inflammatory effects (Razis et al., 2014) 
are some the beneficial properties. Phyllanthus emblica fruit has a high ascorbic content which 45$70 \%$ of it contributes towards its antioxidant activity (Raghu et al., 2007). Also, it is important to know about the phytochemistry as these complex agents interfere in both mineral bioavailability (Allen et al., 2014) and shelf life of dairy products (Peixoto et al., 2011). Many attempts have been made and researches are carried out to use plant sources like Moringa oleifera to improve the health of consumers (ElGammal et al., 2017). In this research both Moringa oleifera and Phyllanthus emblica. L have been used to fulfil daily requirements of minerals like $\mathrm{Ca}, \mathrm{Zn}$ and $\mathrm{Mg}$ and to increase the antioxidant properties of drinking yoghurt. Another parallel series of drinking yoghurt products were made using chemical/pharmaceutical ingredients of $\mathrm{Ca}$ and $\mathrm{Zn}$, to compare the organoleptic properties and shelf life, in aim to decide the better option for a commercial scale production.

\section{Material and Methods}

\section{Material}

Standardized and pasteurized milk (Fat 2.5\%) and cream (Fat 40\%) from Highland (Sri Lankan dairy company) production plant, sugar, sterilized potable water, drinking yoghurt culture (Thermophillic culture), Moringa oleifera leaves, Phyllanthus emblica (fruit), food grade calcium carbonate (SNOWCAL 60, OMYA UK, $\mathrm{CaCO}_{3}$ minimum-97\%, $\mathrm{HCl}$ insoluble residue- $2.2 \%$, moisture- $0.23 \%$, particle size- $45 \mu \mathrm{m})$ and Zinc aspartate from Unizink ${ }^{\circledR} 50$ capsule [Zinc-bis (hydrogen DL- aspartate), $50 \mathrm{mg}$ of enteric coated tablet contains $10 \mathrm{mg}$ of zinc]. All the other chemicals used including the solvent, were of analytical grade. (Gallic acid, Folin-Ciocalteu's phenol reagent, 2,2 -diphenyl-1-picrylhydrazyl (DPPH) etc).

\section{Methods}

\section{Preparation of the Moringa oleifera leaf extract}

The plant derived aqueous extract was prepared at laboratory according to the method described by Najgebauer-Lejko et al., (2011) with few modifications. Five grams of dried leaf powder was mixed with $150 \mathrm{~mL}$ of boiling distilled water and held for 5 minutes inside the boiling water bath while stirring. The mixture was then filtered twice through clean cheese cloths and then through Whatman No. 40 filter paper. Filtered extract was transferred into a sterile beaker. The aqueous extract stock solution can be stored at $4^{\circ} \mathrm{C}$ for up to 5 days.

\section{Preparation of Phyllanthus emblica fruit extract}

Matured Phyllanthus emblica fruits were washed well several times using potable water. Damaged parts were removed using a clean knife. Seeds were removed and fleshes were blended with potable water with $1: 2$ ratio (W/V). Finely blended pulp was heated in a hot water bath for 30 minutes. Pulp was filtered using a clean cheese cloth and the extract was stored under refrigerated condition $\left(4^{0} \mathrm{C}\right)$.

\section{Preparation of drinking yoghurt by incorporating} Moringa oleifera and Phyllanthus emblica extracts/mineral salts (Calcium carbonate and zinc aspartate)

Drinking yoghurts were prepared according to the procedure shown in the Figure 1. Plant extracts were added before the pasteurization. Chemical mineral salts were added under sterile conditions when the curd was breaking. These two were done separately.

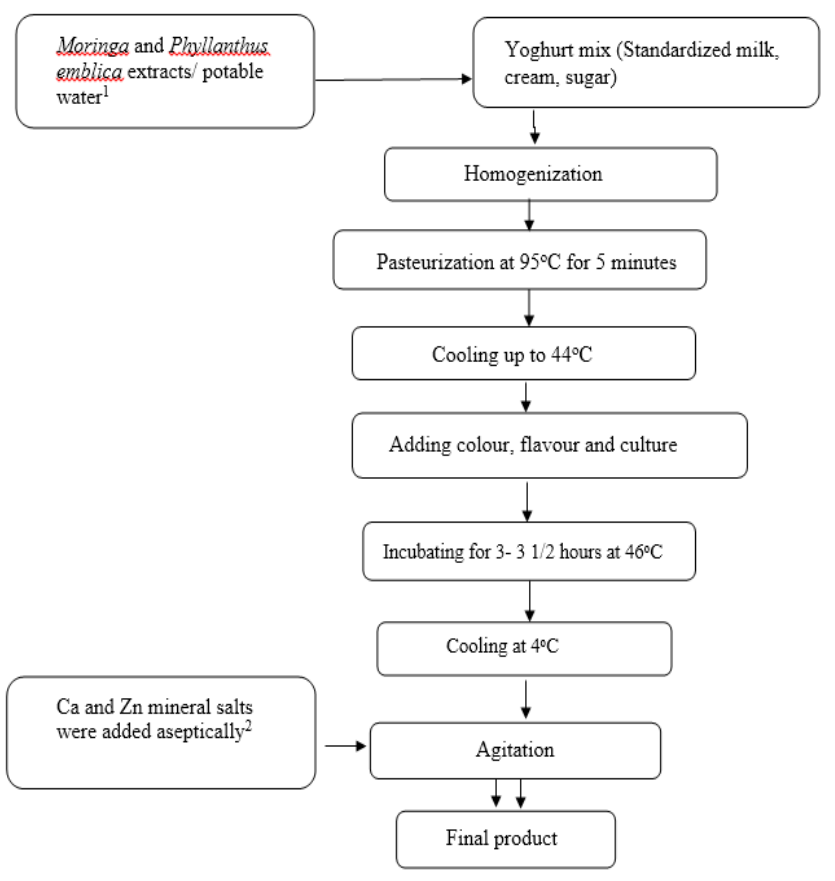

Figure-1 : Preparation of drinking yoghurt using plant extracts/ mineral salts

*1 \& 2 steps are done separately in different production batches 
Formulation of Moringa oleifera leaf extract and Phyllanthus emblica fruit extract for $33 \%, 50 \%$ and $66 \%$ RDI values of Ca per one serving size

Amount of plant extracts that were to be added to the drinking yoghurts were calculated according to the calcium content in the plant extracts analysed during the study. Accordingly, 5.8\%, $12.0 \%$ and $17.8 \%(\mathrm{v} / \mathrm{w})$ of aqueous extract of Moringa oleifera leaf powder and $1.1 \%, 2.4 \%$ and $3.5 \%(\mathrm{v} / \mathrm{w})$ of Phyllanthus emblica fruit extract were added to the yoghurt mixture respectively to fulfil $33 \%, 50 \%$ and $66 \%$ RDI of $\mathrm{Ca} . \mathrm{Zn}$ incorporation was not done for plant based yoghurt production since, addition of rich plant sources of $\mathrm{Zn}$ often interfered with product stability.

Formulation of Calcium carbonate and Zinc aspartate for $33 \%, 50 \%$ and $66 \%$ RDI values of Ca and $\mathrm{Zn}$ per one serving size

Amount of Calcium carbonate and Zinc aspartate from powdered Unizink ${ }^{\circledR} 50$ capsule to be added to the drinking yoghurts were calculated considering the percentage of elemental mineral content available in each compound. Accordingly, 0.24\%, $0.57 \%$ and $0.74 \%(\mathrm{w} / \mathrm{w})$ of calcium carbonate and $0.006 \%$, $0.012 \%$ and $0.017 \%(\mathrm{w} / \mathrm{w})$ of powdered Unizink $\AA$ capsule were added to the yoghurt mixture respectively to fulfil $33 \%, 50 \%$ and $66 \%$ RDI of $\mathrm{Ca}$ and $\mathrm{Zn}$.

\section{Mineral analysis}

$\mathrm{Ca}$ and $\mathrm{Zn}$ content of the plant extracts were determined using flame atomic absorption spectrometer (Model;Thermo SCIENTIFIC) using wet digested samples according to the method followed by Kayaa et al., (2008) with minor modifications. $\mathrm{Ca}, \mathrm{Zn}, \mathrm{Mg}$, Sodium (Na) and Potassium (K) content in drinking yoghurt products were analysed using flame atomic absorption spectrometer while Fe was determined using Graphite furnace atomic absorption spectrometer (Thermo Scientific). Calcium content of the samples was analysed using both wet ashing method followed by Kayaa et al. (2008) with minor modifications and dry ashing method.

\section{Sensory evaluation}

Sensory evaluation of the drinking yoghurt samples fortified with minerals from plant sources and pharmaceutical sources were carried out separately by 30 semi trained panellists from University of Sri Jayewardenepura under the department of Food
Science and Technology on 5 point hedonic scale for different parameters such as appearance, aroma, taste, mouth feel and overall acceptability. Each panellist was given three coded samples with a ballet paper and was asked to provide scores according to their preference. The temperature of samples when served was $4^{\circ} \mathrm{C}$ in order to mimic consumer behaviour.

Another sensory evaluation was carried out using 10 trained panellists who were selected from MILCO (Pvt) Ltd, under the same hedonic scale and sensory characteristics. This was performed to select the best sample from above selected samples in both plant and pharmaceutical series. Scores obtained from the sensory evaluation were analysed using MINITAB 17 statistical software package. Results obtained under the semi trained panel was analysed by the Friedman test while results obtained from the trained panel was analysed by Kruskal walis test. Radar diagrams were drawn according to the sum of rank values and average rank values of each samples which were obtained from Friedman test and Kruskal walis test respectively and their sensory characteristics were compared.

\section{Total phenol content}

Ethanolic extracts of drinking yoghurt samples were prepared by mixing $10 \mathrm{~g}$ of samples with $95 \%$ ethanol using an agitator overnight. Mixture was centrifuged at $3200 \mathrm{rpm}$ for 5 minutes and the supernatant was collected. Total phenol content was determined according to the method developed by Ainsworth and Gillespie (2007). Exactly $1 \mathrm{ml}$ from the test sample (i.e sample supernatants, diluted plant extracts, Gallic acid standards $(20$ ppm, 40 ppm, 60 ppm, 80 ppm and $100 \mathrm{ppm}$ ) and $95 \%(\mathrm{~V} / \mathrm{V})$ ethanol) were added to each test tube. Then $2 \mathrm{ml}$ of Folin-Ciocalteu's reagent was added and vortexed well and $8 \mathrm{ml}$ of $7.5 \%$ sodium carbonate solution was added and kept for 2 hours. After incubation, absorbance of each sample was observed using UV spectrophotometer at $765 \mathrm{~nm}$. Results were expressed as $\mathrm{mg}$ of Gallic acid equivalent per gram of sample (mg GAE/g).

\section{Antioxidant activity}

The DPPH radical scavenging activity of the drinking yoghurt samples and plant extracts was estimated according to the procedure described by McCue and Shetty (2005) with minor modifications. Eight millilitres of ethanolic DPPH. Solution $\left(1.5 \times 10^{-4} \mathrm{M}\right)$ was placed in a test tube and mixed with $2 \mathrm{ml}$ of sample or $95 \%$ ethanol (as control), vortexed well and 
incubated in the dark for 30 minutes at room temperature. Absorbance of each sample was measured at $517 \mathrm{~nm}$.

DPPH Scavenging activity $(\%)=[($ Control absorbanceextract absorbance)/ (Control absorbance)] x 100

\section{Ascorbic acid content}

Titrimetric method of 2, 6 dichlorophenol indophenol dye was used to determine the vitamin $\mathrm{C}$ content.

\section{Physico- chemical properties}

The total solid content, moisture content and ash content were determined. Protein content was determined using kjeldhal method. Fat content was determined according to the Gerber method. Total soluble solid content was determined using the brix meter (Model: Duralab, 0-32\%). The colour reflectance measurement was determined using Lovibond ® LC 100 following the operating instructions of the instrument. The following parameters were defined: L* (lightness; ranging from black (0) to white (100)), a* (red saturation index; $+a^{*}=$ red, $-a^{*}=$ green) and $b^{*}$ (yellow saturation index; $+b^{*}=$ yellow, $\left.-b^{*}=b l u e\right)$. The viscosity of the samples was measured using a Brookfield Viscometer Model DV-II+Pro (Brookfield) at $4^{\circ} \mathrm{C}$. Samples $(300 \mathrm{ml}$ from a sample) were tested using spindle no. 5 with a speed of $20 \mathrm{rpm}$, for a uniform time period of 2 minutes.

\section{Shelf life evaluation}

Shelf life studies were carried out for the drinking yoghurt samples with best sensory properties; selected from plant ingredients and pharmaceutical ingredients. Samples were stored below $4^{0} \mathrm{C}$ and organoleptic properties, $\mathrm{pH}$ (pH meter, Eutech 510), titratable acidity were tested within intervals of 3 days throughout the shelf life. The syneresis was determined according to the centrifuge method as follows:

$$
\text { Syneresis }(\%)=\frac{\text { Whey } \operatorname{lost}^{*}(\mathrm{~g})}{\text { Sample weight }(\mathrm{g})} \times 100
$$

* Whey lost $=$ Weight of the supernatant collected

\section{Microbiological analysis}

Microbiological analysis for the best drinking yoghurt samples selected from plant ingredients and pharmaceutical ingredients were carried out within time intervals throughout the shelf life. Samples were stored below $4{ }^{0} \mathrm{C}$. The count of coliform (ISO 4831:2006) using MPN method, yeast and mould (ISO 6611:2004) and total plate count (ISO 4833:2003) were determined. The colonies were counted using a colony counter and results were expressed in terms of colony forming unit per $\mathrm{ml}$ (cfu/ml).

\section{Statistical analysis}

Data collected were statistically analysed on the basis of ANOVA and nonparametric tests at $95 \%$ significant level using MINITAB 17 statistical software.

\section{Results and Discussion}

\section{Mineral analysis}

Minerals were analysed under flame atomic spectrometer and the concentrations were detected in ppm. $\mathrm{Ca}$ and $\mathrm{Zn}$ contents were significantly higher $(p<0.05)$ in the extract, when Moringa leaves were not blanched prior to preparation of extract. In blanched leaf extract $17.14 \pm 0.01 \mathrm{mg} / \mathrm{ml}$ of $\mathrm{Ca}$ and $0.0021 \pm$ $0.0020 \mathrm{mg} / \mathrm{ml}$ of $\mathrm{Zn}$ were detected while $25.27 \pm 0.25$ $\mathrm{mg} / \mathrm{ml}$ of $\mathrm{Ca}$ and $0.0064 \pm 0.0062 \mathrm{mg} / \mathrm{ml}$ of $\mathrm{Zn}$ were in unblanched leaf extract. However, blanching is advantageous in commercial processing and unblanched leave extracts were having some undesirable organoleptic properties after addition. It was observed that the extract prepared with blanched leaves was greenish while the extract with unblanched was brownish and astringent in taste. Hence, blanched leaves extract was selected to be incorporated to drinking yoghurt due to higher commercial viability. Further, the levels of oxalate, phytate and trypsin inhibitor are reduced through blanching (Sallau et al., 2012). Blanching increases the amount of polyphenols in the plant tissues by reducing oxidative damage. These polyphenols act as naturally occurring antioxidants (Sreelatha and Padma, 2009).

Calcium content in Moringa oleifera dried leaves powder extract was extremely higher than Phyllanthus emblica fruit extract $(0.3305 \pm 0.0089 \mathrm{mg} / \mathrm{ml})$. Zn content in both plant extracts was significantly low. Studies revealed that plant sources have very low $\mathrm{Zn}$ content than animal sources which are more bioavailable (Caulfield and Black, 2004). Hence, enriching $\mathrm{Zn}$ in a dairy product using plant extracts was decided as a non-viable option commercially and practically. $\mathrm{Zn}$ fortification was done using pharmaceutical sources in the next product series. 
Jayani Samarathunga et al.

Table -1: Mineral composition of final products ( $1 \mathrm{cup}=170 \mathrm{~g}$ of drinking yoghurt)

\begin{tabular}{|c|c|c|c|c|c|c|}
\hline Sample & $\begin{array}{c}\text { Ca } \\
\mathbf{m g} / \mathbf{c u p} \pm \text { SD }\end{array}$ & $\begin{array}{c}\mathbf{Z n} \\
\mathbf{m g} / \mathbf{c u p} \pm \mathbf{S D}\end{array}$ & $\begin{array}{c}\mathbf{M g} \\
\mathbf{m g} / \mathbf{c u p} \pm \mathbf{S D}\end{array}$ & $\begin{array}{c}\mathbf{F e} \\
\mathbf{m g} / \mathbf{c u p} \pm \mathbf{S D}\end{array}$ & $\begin{array}{c}\mathbf{\text { Na }} \\
\mathbf{m g} / \mathbf{c u p} \pm \mathbf{S D}\end{array}$ & $\begin{array}{c}\mathbf{K} \\
\mathbf{m g} / \mathbf{c u p} \pm \mathbf{S D}\end{array}$ \\
\hline $\mathbf{P 3 3 \%}$ & $311.50 \pm 0.04$ & $3.04 \pm 0.05$ & $182.69 \pm 0.69$ & $6.38 \pm 0.09$ & $180.74 \pm 0.40$ & $255.55 \pm 1.75$ \\
\hline P50\% & $451.65 \pm 0.66$ & $4.95 \pm 0.00$ & $266.58 \pm 0.89$ & $10.09 \pm 0.03$ & $217.67 \pm 0.76$ & $236.83 \pm 0.22$ \\
\hline P66\% & $630.82 \pm 1.40$ & $5.36 \pm 0.34$ & $431.18 \pm 0.72$ & $12.72 \pm 0.31$ & $234.61 \pm 0.12$ & $229.77 \pm 2.21$ \\
\hline Control & $129.75 \pm 0.71$ & $0.43 \pm 0.00$ & $181.13 \pm 0.42$ & $3.41 \pm 0.07$ & $172.21 \pm 0.14$ & $198.25 \pm 1.20$ \\
\hline M 33\% & $283.64 \pm 0.11$ & $0.89 \pm 0.00$ & $181.31 \pm 0.62$ & $3.54 \pm 0.07$ & $125.35 \pm 0.43$ & $217.42 \pm 5.81$ \\
\hline M 50\% & $434.99 \pm 3.36$ & $1.56 \pm 0.00$ & $183.38 \pm 0.17$ & $5.64 \pm 0.28$ & $170.40 \pm 0.24$ & $204.62 \pm 0.83$ \\
\hline M 66\% & $514.45 \pm 1.28$ & $2.17 \pm 0.06$ & $186.14 \pm 0.81$ & $8.68 \pm 0.21$ & $169.75 \pm 2.22$ & $210.48 \pm 0.05$ \\
\hline
\end{tabular}

(Mean values of $\mathrm{n}=3 \pm$ Standard Deviation. P33\%, P50\% and P66\% in the table denote the pharmaceutical ingredients added drinking yoghurts made fortified with 33\%, 50\% and 66\% RDI levels of calcium and zinc respectively. 'Control' indicates the plain drinking yoghurt. M 33\%, M 50\% and M 66\% denote drinking yoghurts fortified with plant extracts at 33\%, 50\% and 66\% RDI levels of calcium respectively).

Although Phyllanthus embilica extract elicited low values of both $\mathrm{Ca}$ and $\mathrm{Zn}$, implying it as an unsuitable option to incorporated, it was not ignored due to high antioxidant content estimated to be contributed by it. As shown in the Table 1, pharmaceutical ingredients addition had increased the mineral composition rather than plant extracts done. Incorporation of plant ingredients had not increased the $\mathrm{Mg}$ content in the final product and since many pharmaceutical supplements have binding agent which could include $\mathrm{Mg}$, pharmaceutical ingredients had increased the $\mathrm{Mg}$ content of the products. For good health, best way is to get more potassium and less sodium (Perez and Chang, 2014). Accordingly, all the above products had maintained healthy sodium to potassium ratio. The above results indicate that Moringa oleifera leaf extract and Phyllanthus emblica fruit extract addition is helpful in increasing the $\mathrm{Fe}$ content of the final products.

When comparing the results using two methods, results of dry ashing method had shown comparatively lower calcium contents ( P33\%- 257.89 \pm 0.62, P50\%-

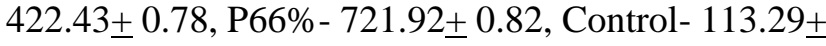

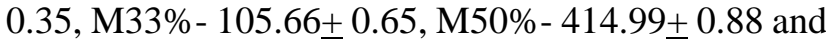
M66\%- 512.45 $0.24 \mathrm{mg} / \mathrm{cup}$ ) than results of the wet ashing method. Some studies revealed that considerable losses can occur during dry ashing method in yoghurt samples under $500{ }^{\circ} \mathrm{C}$ due to high temperature (Kayaa et al., 2008). Although most bioavailable and soluble organic salt was tricalcium citrate, $\mathrm{CaCO}_{3}$ was used when preparing pharmaceutical ingredient fortified drinking yoghurts since it was cheap, highly available and has $40 \%$ of elemental calcium (Gerhart and Schottenheimer, 2013). In the study, calcium carbonate was added in the curd breaking process under aseptic conditions. In that stage $\mathrm{pH}$ of the curd is lower due to the formation of lactic acid. Since the solubility of calcium carbonate is high in lower $\mathrm{pH}$, it was added in the curd breaking process without adding it at the beginning. As a result, sediments were not formed. If calcium carbonate was added before the pasteurization process, due to high temperature calcium caseinate will be precipitated at its isoelectric point and milk coagulates. This will not give correct texture. Zinc aspartate from Unizink ${ }^{\circledR} 50$ capsule, a common pharmaceutical with good bioavailability was selected as the $\mathrm{Zn}$ source. Other sources like Zinc sulphate and Zinc oxide are less soluble, less bioavailable and give off tastes.

\section{Sensory evaluation for selecting the best product from plant ingredient and pharmaceutical ingredient fortified drinking yoghurts}

Sensory properties of the three products incorporated with different amount of plant extracts were compared among each other along with the plain drinking yoghurt (control), using a panel of 30 semi trained panellists on 5 point hedonic scale for different sensory properties such as appearance, aroma, taste, mouthfeel and overall acceptability. Results were obtained from the Friedman test and Kruskal walis test. Evaluation of sensory attributes for drinking yoghurts fortified with plant ingredients and pharmaceutical ingredients are shown in the radar diagrams below.

The radar diagram in figure 2 and figure 3 were drawn according to the sum of rank values obtained from the friedman test. Sensory attributes such as appearance, taste, mouth feel and overall acceptability have significant differences among samples $(\mathrm{p}<0.05)$. Aroma of the samples has not shown significant difference among samples ( $p>0.05)$. 


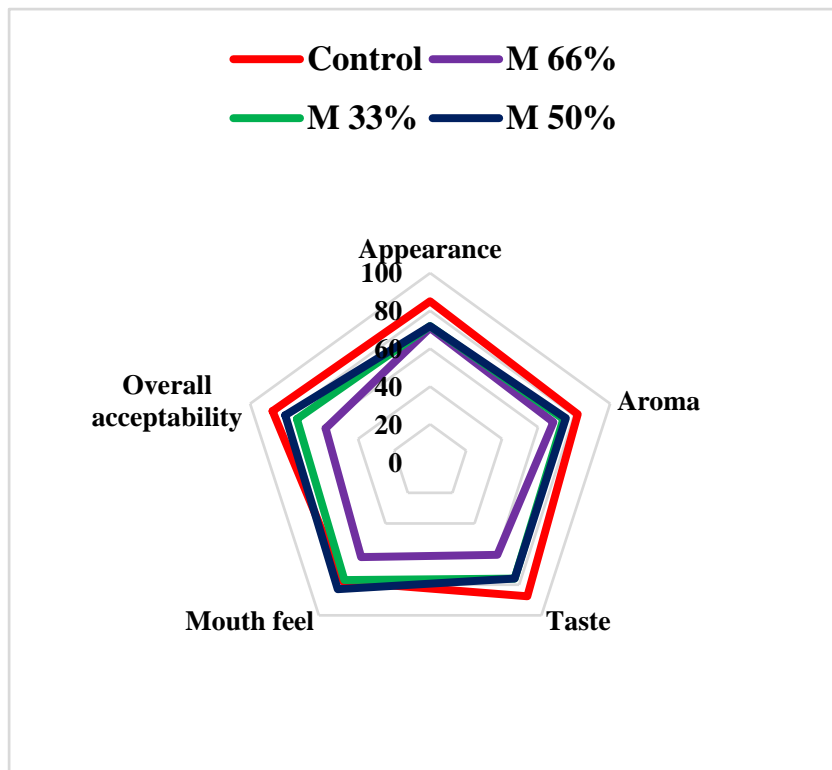

Figure-2: Radar diagram of the plant ingredient fortified drinking yoghurts

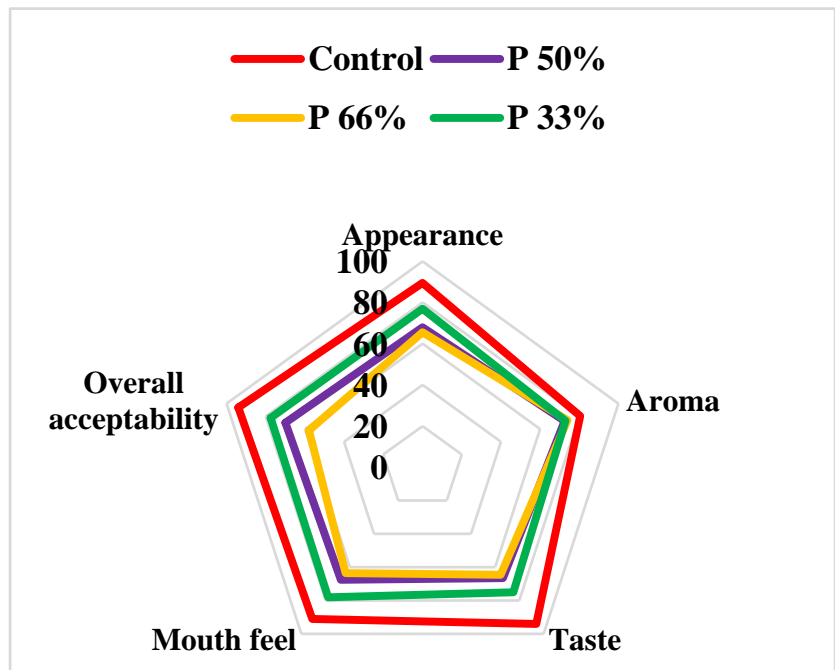

Figure-3: Radar diagram of the pharmaceutical ingredient fortified drinking yoghurts

NOTE: The terms of the above are described as follows. Control- Plain drinking yoghurt, M66\%Plant ingredient drinking yoghurt fortified with $66 \%$ RDI Ca, M33\% -Plant ingredient drinking yoghurt fortified with 33\% RDI Ca, M50\% -Plant ingredient drinking yoghurt fortified with 50\% RDI Ca., P66\%Pharmaceutical ingredient drinking yoghurt fortified with 66\% RDI $\mathrm{Ca}$ and $\mathrm{Zn}, \mathrm{P} 33 \%$-Pharmaceutical ingredient drinking yoghurt fortified with $33 \% \mathrm{RDI} \mathrm{Ca}$ and $\mathrm{Zn}, \mathrm{P} 50 \%$-Pharmaceutical ingredient drinking yoghurt fortified with 50\% RDI Ca and Zn.

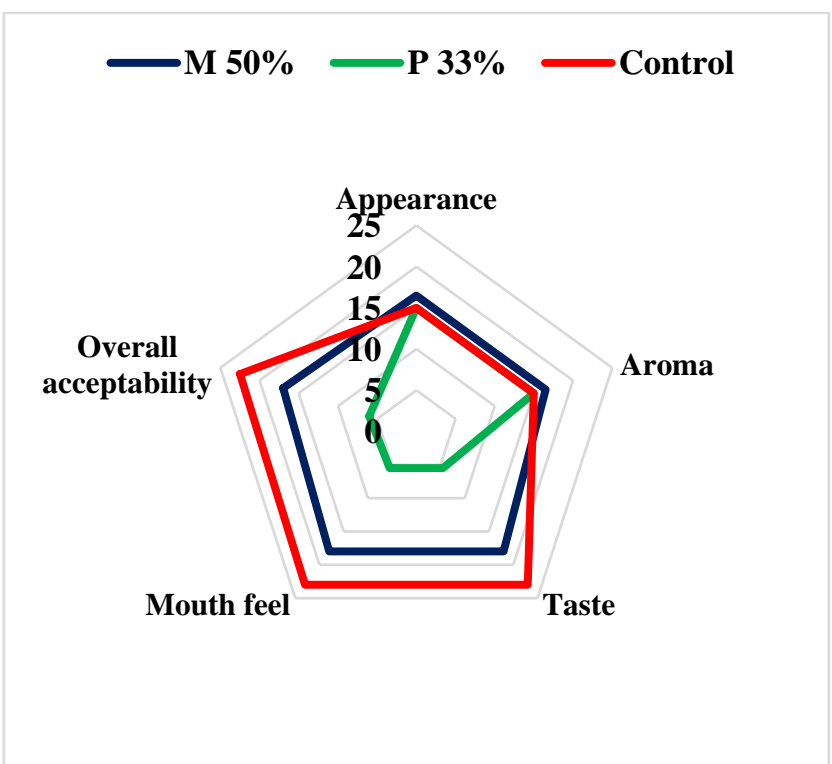

Figure-4: Radar diagram which compare the sensory properties of best samples selected from plant and pharmaceutical sources

When considering the overall acceptability, rank values varied as control> M50\% > M33\% > M66\%. Mouth feel of the sample M 50\% had obtained the highest rank. For drinking yoghurt like product, mouth feel plays a major role among consumers in the market. Therefore, M50\% was selected as the best sample.

Sensory properties of the three products fortified with different amount of pharmaceutical ingredients were compared among each other along with the plain drinking yoghurt (control), using a panel of 30 semi trained panellists on 5 point hedonic scale for same sensory properties as above. Results obtained from the Friedman test were represented in figure 3. According to the results, sensory attributes like appearance, taste, mouth feel and overall acceptability have significant differences among samples $(\mathrm{p}<0.05)$. Aroma of the samples has not shown significant difference between samples $(p>005)$. When consider the overall acceptability rank values, varied as control> P33\% > $\mathrm{P} 50 \%>\mathrm{P} 66 \%$. P33 \% sample has the highest rank among samples fortified with pharmaceutical mineral salts. Therefore, P33\% was selected as the best sample. 
Jayani Samarathunga et al.

The selected two best samples from the two respective product series (M50\% and P33\%) were then again compared using Kruskal-Wallis test for their sensory properties using 10 trained panellists. Results were interpreted in the figure 4. According to the results, most acceptable sample was the control. From the two sources used for the fortification, fortification of $\mathrm{Ca}$ using plant sources M50\% has shown more sensory acceptable characteristics than when incorporated with pharmaceutical sources of $\mathrm{Zn}$ and $\mathrm{Ca}$ to drinking yoghurt P33\%.

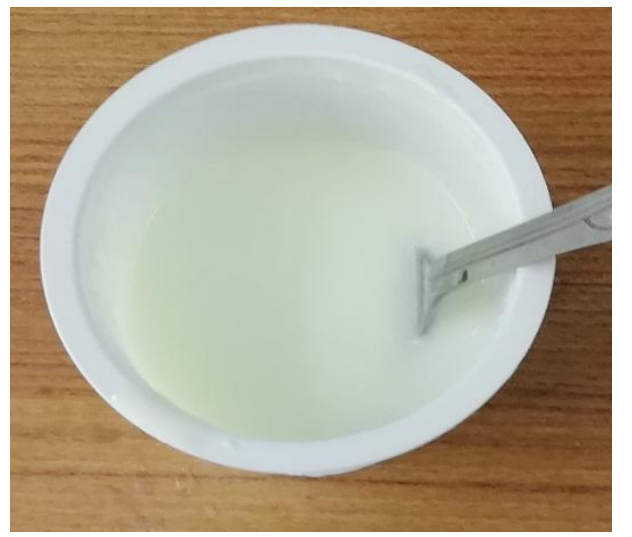

Figure 5: Best plant ingredients fortified drinking yoghurt (M 50\%)

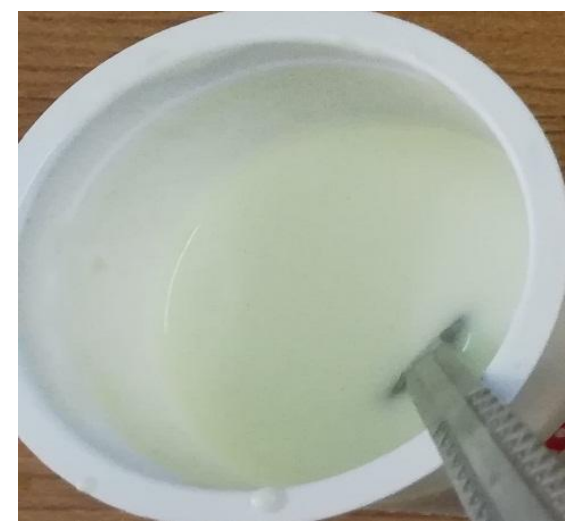

Figure 6: Best pharmaceutical ingredients fortified drinking yoghurt (P 33\%)

\section{Total phenolic content (TPC)}

From the plot drawn for the change in absorbance against concentration (Absorbance $=0.02710+9.006$ concentration $\mathrm{mg} / \mathrm{ml}$ ), TPC present in Moringa leaf extract (94.85), Phyllanthus emblica fruit extract (118.97) and final products (Control- 1.34, M33\%2.29, M50\%-3.17, M66\%- 3.60) were calculated in $\mathrm{mg}$ GAE/g (Milligram of Gallic acid equivalents per gram of sample) . M 50\% sample which was selected as the best product in the sensory analysis, had increased the TPC from $1.34 \mathrm{mg} \mathrm{GAE} / \mathrm{g}$ to $3.17 \mathrm{mg}$ GAE/g. Consumption of one cup (170 mL) of M50\% drinking yoghurt, would provide $538.9 \mathrm{mg}$ of GAE.

\section{Antioxidant activity}

Some researchers emphasize that there is a positive correlation between total phenolic contents and free radical scavenging activity of the fruit extracts (Caillet et al., 2006). Results of this study reveals that, Phyllanthus emblica fruit extract $(83.65 \% \pm$ $0.01)$ has significantly higher $(\mathrm{p}<0.05) \quad \mathrm{DPPH}^{-}$ scavenging activity than Moringa leaf extract (37.54\% \pm 0.02). Although Phyllanthus fruit extract didn't contribute by increasing either $\mathrm{Ca}$, or $\mathrm{Zn}$ in the final product significantly, the rich antioxidant concentration was a prominent reason to incorporate it to the drinking yoghurt. Antioxidant activity had increased with the incorporating level of plant extracts (Range: $52.08 \% \pm 0.02-91.69 \% \pm 0.00)$ and had decreased with the incorporating level of pharmaceutical ingredients (Range: $4.64 \% \pm 0.72-2.25 \% \pm 0.09$ ). Plain drinking yoghurt also showed lower antioxidant activity $(6.55 \% \pm 0.34)$.

Milk proteins are good source of essential amino acids. They contain bioactive peptides that are liberated from casein and whey proteins by enzymatic hydrolysis with digestive enzymes or by the fermentation of milk by proteolytic starter cultures and the action of enzymes derived from these microorganisms. These peptides act as antioxidants as well (Unal and Akalın, 2012).

\section{Ascorbic acid content}

Ascorbic acid content of the best drinking yoghurt product fortified with plant extracts $(55.50 \pm 0.00$ $\mathrm{mg} / 100 \mathrm{~g}$ ) was 10 times higher than the plain drinking yoghurt $(5.55 \pm 0.00 \mathrm{mg} / 100 \mathrm{~g})$. Ascorbic acid contributes to the antioxidant activity as well. Ascorbic acid content of Phyllanthus emblica fruit extract $(66.60 \pm 0.00 \mathrm{mg} / 100 \mathrm{~g})$ was higher than Moringa leaf extract $(16.65 \pm 0.00 \mathrm{mg} / 100 \mathrm{~g})$. Phyllanthus emblica fruit extract was having noticeable ascorbic acid content even after heat treatment was done in yoghurt preparation; providing another valid reason to use it as a major ingredient.

\section{Proximate composition}

Proximate analysis was carried out for the best product (M 50\%) selected from the sensory evaluation; as it 
Jayani Samarathunga et al.

was the best product to commercialize when overall properties are considered. Fat content in the drinking yoghurt fortified with plant sources had decreased compared to the plain drinking yoghurt while protein content had increased. Addition of aqueous extracts had resulted high moisture content in the final product. In the fortified product, plant extracts were added replacing small amount of milk that was required to prepare plain drinking yoghurt. Therefore, the total solid content and total soluble content was lower and since plant extracts had more mineral content higher ash content been determined.

Table-2: Proximate composition of the final products and plant extracts

\begin{tabular}{|c|c|c|c|c|}
\hline Constituents & $\begin{array}{c}\text { Moringa } \\
\text { oleifera leaf } \\
\text { extract }\end{array}$ & $\begin{array}{c}\text { Phyllanthus } \\
\text { emblica fruit } \\
\text { extract }\end{array}$ & $\mathbf{M ~ 5 0 \%}$ & Control \\
\hline Fat & $\mathrm{ND}$ & $\mathrm{ND}$ & $2.20 \pm 0.03$ & $2.5 \pm 0.00$ \\
\hline Protein & $2.51 \pm 0.01$ & $0.34 \pm 0.08$ & $4.68 \pm 0.00$ & $3.58 \pm 0.02$ \\
\hline Constituents & $\begin{array}{c}\text { Moringa } \\
\text { oleifera leaf } \\
\text { extract }\end{array}$ & $\begin{array}{c}\text { Phyllanthus } \\
\text { emblica fruit } \\
\text { extract }\end{array}$ & $\mathbf{M ~ 5 0 \%}$ & Control \\
\hline Moisture & - & - & $87.14 \pm 0.07$ & $79.56 \pm 0.03$ \\
\hline Ash & - & - & $1.04 \pm 0.01$ & $0.57 \pm 0.00$ \\
\hline Total Solid content & - & - & $18.54 \pm 0.01$ & $20.30 \pm 0.01$ \\
\hline Total soluble solid & $2 \%$ & $6 \%$ & $17.00 \pm 0.00$ & $18.00 \pm 0.00$ \\
\hline content & & 6 &
\end{tabular}

(Mean values of $n=3 \pm$ Standard Deviation, ND* Not Detected)

\section{Viscosity}

Viscosity is an essential quality parameter to maintain properly for a product like drinking yoghurt. Stability of these products was evaluated based on the viscosity and syneresis. Sensory properties such as mouth feeling, thickness are greatly impacted by the viscosity. When adding an aqueous extract like Moringa oleifera leaf extract and Phyllanthus emblica fruit extract in the preparation of drinking yoghurt, viscosity decreased $(1000.00 \pm 0.00$ to $800.00 \pm 0.00$ $\mathrm{mPas})$. Usually, drinking yoghurt is low viscous than a set yoghurt. Favourable viscosity for a commercial product is elicited by the control $(1000.00 \pm 0.00 \mathrm{mPas})$ since it was prepared according to a product in the market. In drinking yoghurt products fortified with pharmaceutical sources, viscosity increased with the incorporation level $(800.00 \pm 0.00$ to $1000.00 \pm 0.00$ mPas).

\section{Colour}

Incorporation of aqueous extract instead of powder was to increase the solubility and the colour effect was minimum. Lightness of M50\% sample $(\mathrm{L}=67.1 \pm 0.1$, has decreased due to the incorporation of plant extracts (Control $\mathrm{L}=69.5 \pm 0.1$ and $\mathrm{P} 33 \% \mathrm{~L}=70.8 \pm 0.0$ ). All $\mathrm{a}^{*}$

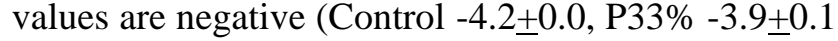
and $\mathrm{M} 50 \%-4.2 \pm 0.0)$ representing the green colour of the samples while all $\mathrm{b}^{*}$ values are positive( Control $12.3 \pm 0.01, \mathrm{P} 33 \% 12.2 \pm 0.0$ and M50\% 13.5 \pm 0.0 ) representing the yellow colour. Overall, this indicates that colour of all the samples have not disturbed the natural drinking yoghurt colour. There was no significant difference between fortified drinking yoghurt and plain drinking yoghurt in relation to the colour. Therefore, colouring agents can be added to final products as necessary.

\section{Shelf life evaluation}

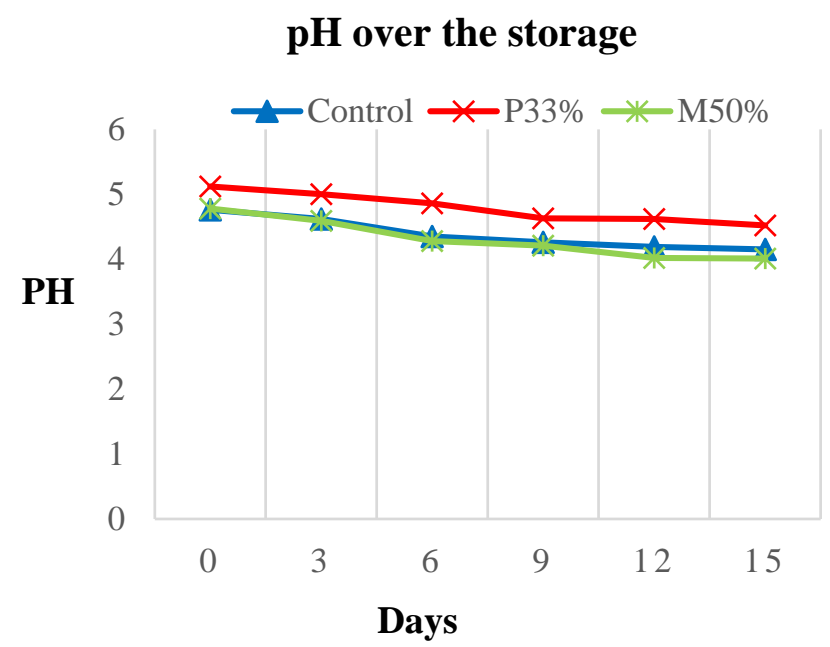

Figure-7: pH variation of final products over storage period

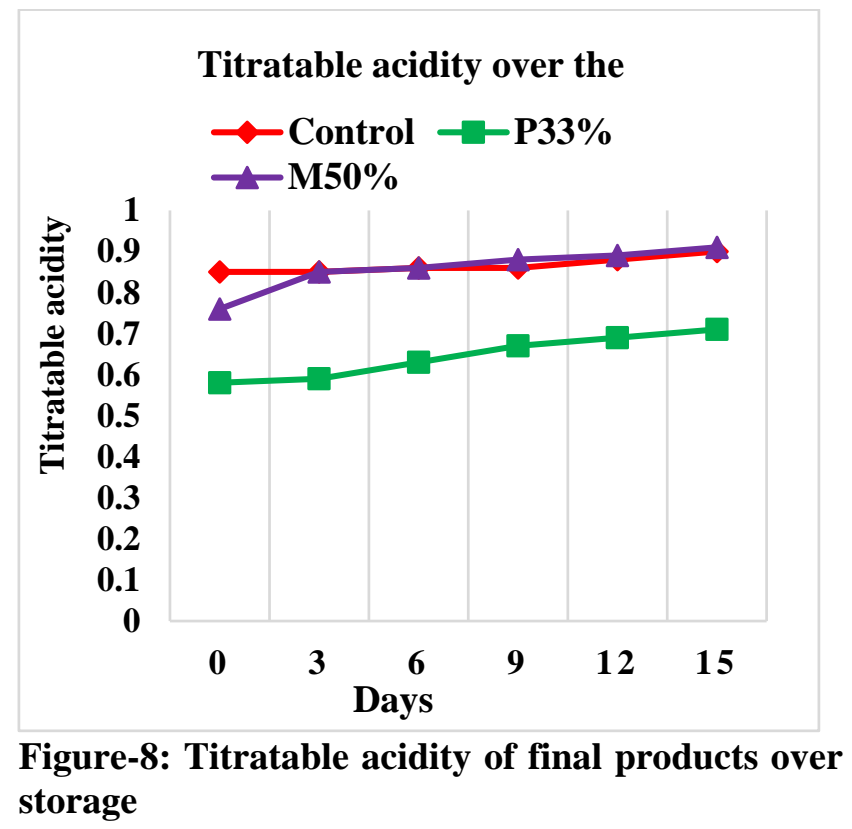


Table-3: Total plate count of final products over the storage period

\begin{tabular}{|c|c|c|c|c|c|}
\hline \multirow{2}{*}{$\begin{array}{c}\text { Total plate } \\
\text { count }\end{array}$} & Sample & 0 & \multicolumn{4}{|c|}{ Days } \\
\cline { 2 - 6 } & & & 5 & 10 & 15 \\
\cline { 2 - 6 } & Control & $1.49 \pm 0.01$ & $2.34 \pm 0.01$ & $4.76 \pm 0.03$ & $5.95 \pm 0.01$ \\
\cline { 2 - 6 } & $\mathrm{P} 33 \%$ & $1.44 \pm 0.01$ & $2.25 \pm 0.01$ & $4.69 \pm 0.02$ & $5.92 \pm 0.01$ \\
\cline { 2 - 6 } $\mathbf{1 0})$ & $\mathrm{M} 50 \%$ & $1.42 \pm 0.01$ & $2.28 \pm 0.02$ & $4.58 \pm 0.03$ & $5.93 \pm 0.00$ \\
\hline
\end{tabular}

(Mean values of $n=3 \pm$ Standard Deviation)

As shown in the figure 7, $\mathrm{pH}$ values of all the products gradually decreased due to fermentation. During the shelf life pharmaceutical ingredient fortified yoghurt elicited higher $\mathrm{pH}$ values since calcium carbonate created an alkaline condition. This nature affected the taste of the product however it didn't give an unfavourable flavour.

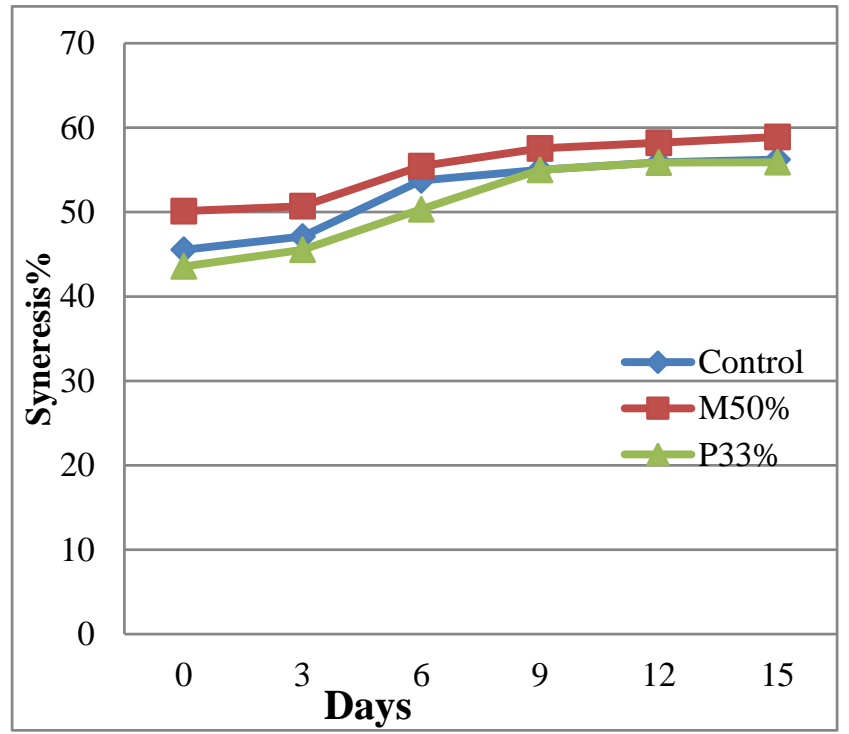

Figure-9: Syneresis of the drinking yoghurts during storage period

During the storage life of 14 days at $4^{0} \mathrm{C} \pm 1, \mathrm{pH}$ values of both control and M50\% have shown similar variations. $\mathrm{pH}$ values of drinking yoghurt samples fortified with pharmaceutical sources (P33\%) were higher. When calcium carbonate was added to the curd of the drinking yoghurt, $\mathrm{pH}$ of the yoghurt has increased slightly possibly due to the alkalinity of carbonate ions. Acidity increases during the shelf life with the production of lactic acid due to the fermentation by lactic acid bacteria. Both control and M50\% sample have similar variations of acidity during the storage period while $\mathrm{P} 33 \%$ remained with lower titratable acidity value at the end of the shelf life. Sourness of the drinking yoghurt increases with the increment of acidity.

\section{Syneresis}

Whey syneresis is an important parameter that determines the stability of a product. It has increased during the storage period. Whey syneresis was higher $(50.11 \%)$ in $\mathrm{M} 50 \%$ than the control $(45.54 \%)$ and P33\% (43.56\%).

\section{Microbial count}

Coliform test has shown negative results for the presence of coliforms/E.coli during the storage period. SLS 516 Part 12: 2013 (ISO 7251: 2005) states the E.coli maximum limit in yoghurt products as 0.3 MPN/g. According to the SLS 516 Part 2: Sec 1: 2013 (ISO 21 527-1,2: 2008), specified by Sri Lanka Standard Institute, yeast and mould count limit in yoghurt should be less than $10 \mathrm{cfu} / \mathrm{g}$ throughout the storage period. In both plant ingredient and pharmaceutical ingredient fortified drinking yoghurts, no yeast and mount counts were recorded during the shelf life. Drinking yoghurts were incorporated with a thermophilic starter culture. The number of viable cells in freeze-dried DVS (Direct vat set) culture was $\min 5 \times 10^{10} \mathrm{cfu} / \mathrm{g}$. Total plate count in M50\%, P33\% and plain drinking yoghurt have increased throughout the storage period. Although the plain drinking yoghurt has recorded higher count than the plant and pharmaceutical ingredient incorporated drinking yoghurts, the effect of treatment was not significant ( $>0.05 \%$ ). During the incubation period of yoghurt manufacturing process, the growth of Lactobacillus bulgaricus and Streptococcus thermophilus was increased and decreased gradually after cooling up to $4{ }^{0} \mathrm{C}$. Here after the total viable count increased due to the activity of other microbes that might enter from the environment. Contaminations could be one such root cause which leads to reduction of the shelf life.

\section{Conclusion}

In this study, $\mathrm{Zn}$ content of Moringa oleifera leaf powder extract and Phyllanthus emblica fruit extract were determined and was found significantly low in content. Due to this reason $\mathrm{Zn}$ fortification was not done using those plant sources. But, when analysing the $\mathrm{Zn}$ content of the final product produced with plant extracts $\mathrm{Zn}$ content had increased significantly than the plain drinking yoghurt. This reveals that 
Jayani Samarathunga et al.

incorporation of plant sources can increase the $\mathrm{Zn}$ content to a considerable extent. Pharmaceutical grade calcium salts have to be added in the stage of curd breaking as coagulation may occur at higher calcium levels by the formation of calcium casinate at its isoelectric point. It is more cost effective and provide good sensory properties when Moringa oleifera and Phyllanthus emblica are used in Calcium fortification. They improve antioxidant activity and ascorbic acid contents significantly as well. Drinking yoghurt fortified with plant sources have shown better sensory properties than drinking yoghurt fortified with pharmaceutical sources. A drinking yoghurt product with high sensory acceptability can be made using the above two sources, as it would provide $50 \%$ RDI in Calcium.

\section{Acknowledgement}

We are extremely grateful to Dr. Asitha Cooray and all staff members of the Instrument centre at Faculty of Applied Sciences, University of Sri Jayewardenepura, Sri Lanka; for providing necessary facilities. We are also thankful to Dr. R.A.U.J. Marapana and Dr. Rupika Perera and Mrs. Hasanthika Sandarenu at the Department of Food Science and Technology, Faculty of Applied Sciences - USJP, Sri Lanka; for their technical support. We express our sincere gratitude for the staff at MILCO Lanka (Pvt) Ltd as well, for their facilitation.

Disclaimer: None.

Conflict of Interest: None.

Source of Funding: None.

\section{References}

Ackley S, Barreit-Connor E and Suarez L, 1983. Dairy products, calcium, and blood pressure. Am. J. Clin. Nutr. 38:457-461.

Ainsworth E and Gillespie K, 2007. Estimation of total phenolic content and other oxidation substrates in plant tissues using Folin-Ciocalteu reagent. Nat. Protoc. 2(4):875-877.

Allen J, Issa J and Cai W, 2014. Calcium content, in vitro digestibility, and bioaccessibility in leaves of spinach (Spinacia oleracea), sweet potato (Ipomea batatas), and drumstick tree (Moringa oleifera). $\quad$ F1000 Research 3: 65. https://doi.org/10.12688/f1000research.3287.1

Caillet S, Salmieri S and Lacroix M, 2006. Evaluation of free radical- scavenging properties of commercial grape phenol extracts by a fast colorimetric method. J. Food Chem. 95(1): 1-8.

Caulfield LE and Black BE, 2004. Zinc deficiency, pp 257-279. Comparative Quantification of Health Risks, World Health Organization, Geneva, Switzerland.

Deeth HC and lewis MJ, 2014. Practical consequences of calcium addition to and removal from milk and milk products. Int. J. Dairy Technol. 67:1-10.

El-Gammal RE, Abdel-Aziz ME and Darwish MS, 2017. Utilization of Aqueous Extract of Moringa oleifera for Production of Functional Yogurt. J. Food Dairy Sci. Mansoura Univ. 8 (1): 45- 53.

FAO/WHO (Food and Agriculture Organisation/World Health Organization), 2002. Human Vitamin and Mineral Requirements, Report of a Joint FAO/WHO Expert Consultation. FAO/WHO, Bangkok, Thailand.

Gee Ong M, Jalil RA, Ishak WSW, Hamid NA, Aziz CBA, Nik WSW, Hamid NF, Malik V, Willet W and $\mathrm{Hu} \mathrm{F}, 2019$. Elemental analysis of commercially available rice samples in Malaysia by using ICP-MS and SEM-EDX. Asian J. Agric. Biol. 7(2): 269-278.

Gerhart M and Schottenheimer M, 2013. Mineral fortification in dairy. pp 30-36. Wellness Foods Eur. Harnisch, USA.

Kayaa G, Akdenizb I and Yaman M, 2008. Determination of $\mathrm{Cu}, \mathrm{Mn}$ and $\mathrm{Pb}$ in Yogurt Samples by Flame Atomic Absorption Spectrometry Using Dry, Wet, and Microwave Ashing Methods. Atom. Spectrosc. 29(3): 99-106.

Larsson C and Johansson G, 2002. Dietary intake and nutritional status of young vegans and omnivores in Sweden. Am. J. Clin. Nutr. 76(1): 100-6.

McCue PP and Shetty K, 2005. Phenolic antioxidant mobilization during yogurt production from soymilk using kefir cultures. Process Biochem. 40: 1791-1797.

Meister MSK, 1997. Vegetarianism, pp 1-33. American Council on Science and Health, USA.

Najgebauer-Lejko D, Sady $M$, Grega $T$ and Walczycka M, 2011. The impact of tea supplementation on microflora, $\mathrm{pH}$ and antioxidant capacity of yoghurt. Int. Dairy J. 21: 568-574.

Otten JJ, Hellwig JP and Meyers LD, 2006. Dietary Reference Intake, pp 8-1344. Institute of Medicine of the National Academies, USA.

Pakade V, Cukrowska E and Chimuka L, 2013. 
Jayani Samarathunga et al.

Comparison of antioxidant activity of Moringa oleifera and selected vegetables in South Africa.

S. Afr. J. Sci. 109(3/4): 1-5.

Peixoto JR, Silva GC and Costa RA, 2011. In vitro antibacterial effect of aqueous and ethanolic Moringa leaf extracts. Asian Pac. J. Trop. Med. 4: 201-204.

Perez V and Chang E, 2014. Sodium-to-Potassium Ratio and Blood Pressure, Hypertension, and Related Factors. Adv. Nutr. 5(6): 712-741.

Phillips F, 2005. Vegetarian nutrition. pp 132-167, vol. 30.British Nutrition Foundation, London, UK.

Raghu V, Platel K and Srinivasan K, 2007. Comparison of ascorbic acid content of Emblica officinalis fruits determined by different analytical methods. J. Food Compos. Anal. 20: 529-533.

Razis AFA, Ibrahim MD and Kntayya SB, 2014. Health benefits of Moringa oleifera. Asian Pac. J. Cancer P. 15 (20): 8571-8576.

Ruby M, 2012. Vegetarianism. A blossoming field of study. Appetite. 58(1):141-150.

Sallau AB, Mada, Ibrahim S and Ibrahim U, 2012. Effect of Boiling, Simmering and Blanching on the Antinutritional Content of Moringa oleifera Leaves. Int. J. Food Nutr. Safet. 2(1): 1-6.

Scheers N, 2013. Regulatory Effects of $\mathrm{Cu}, \mathrm{Zn}$, and $\mathrm{Ca}$ on Fe Absorption: The Intricate Play between Nutrient Transporters. J. Nutr. 5(3): 957-970.

Scrimshaw N, 1996. Human protein requirements: a brief update. Food Nutr. Bull. 17: 185-90.

Sindu M, Farooq U, Shafi A, Akram K, Hayat Z, Riaz $M$ and Shahbaz M, 2019. A comparative, in-vivo anti-diabetic study of persimmon peel powder in alloxan induced rabbits. Asian J. Agric. Biol. 7(2): 176-182.

Sreelatha S and Padma P, 2009. Antioxidant Activity and Total Phenolic Content of Moringa oleifera Leaves in Two Stages of Maturity. Plant Food Hum. Nutr. 64(4): 303-311.

Tende JA, Ezekiel I, Dikko AAU, 2011. Effect of ethanolic leaves extract of Moringa oleifera on blood glucose levels of streptozotocin-induced diabetics and normoglycemic Wistar rats. Brit. J. Pharmacol. Toxicol. 2: 1-4.

Unal $G$ and Akalın AS, 2012. Antioxidant and angiotensin-converting enzyme inhibitory activity of yoghurt fortified with sodium calcium caseinate or whey protein concentrate. Dairy Sci. Technol. 92: 627-639.

\section{Contribution of Authors}

Samarathunga J: Conducted all laboratory experiments and edited and wrote the article Jayasinghe M: Supervised and guided research Edirisinghe M: Provided technical facilities and helped making food products

Wijesekara I: Guided the research team in antioxidant determination activities

Abeysundara P: Guided the research team in shelf life analysis

Shafi A: Provided literature support in the study and helped in article writing

Farooq U: Helped in manuscript write up and final approval of article

Senadheera S: Conceived the research idea and guided the team study design 